\title{
Detection of the CMT1A/HNPP recombination hotspot in unrelated patients of European descent
}

Vincent Timmerman, Bernd Rautenstrauss, Lawrence T Reiter, Thearith Koeuth, Ann Löfgren, Thomas Liehr, Eva Nelis, Klaus D Bathke, Peter De Jonghe, Holger Grehl, Jean-Jacques Martin, James R Lupski, Christine Van Broeckhoven

\section{Laboratory of \\ Neurogenetics, Flanders \\ Interuniversity \\ Institute of \\ Biotechnology (VIB), \\ Born-Bunge \\ Foundation (BBS), \\ University of Antwer \\ (UIA), Department of \\ Biochemistry, \\ Antwerpen, Belgium \\ V Timmerman \\ A Löfgren \\ E Nelis \\ $P$ De Jonghe \\ C Van Broeckhoven \\ Institute of Human \\ Genetics and \\ Department of \\ Neurology, Friedrich- \\ Alexander-University, \\ Erlangen, Germany \\ B Rautenstrauss \\ $T$ Liehr \\ K D Bathke \\ H Grehl}

Department of Molecular and Human

Genetics, Baylor

College of Medicine

Houston, Texas, USA

L T Reiter

T Koeuth

J R Lupski

Division of Neurology, University Hospital

Antwerp (UZA),

Antwerpen, Belgium

$P$ De Jonghe

Laboratory of

Neuropathology, Born-

Bunge Foundation,

University of Antwerp

(UIA), Department of

Medicine, Antwerpen,

Belgium

J-J Martin

Department of

Pediatrics, Human

Genome Center,

Baylor College of

Medicine, Houston,

USA

J R Lupski

Correspondence to:

Professor Van Broeckhoven Laboratory of

Neurogenetics, University of Antwerp (UIA), Departmen of Biochemistry,

Universiteitsplein 1, B-2610

Antwerpen, Belgium.

Received 23 May 1996

Revised version accepted

for publication

7 August 1996

\section{Abstract}

Charcot-Marie-Tooth type 1 disease (CMT1) and hereditary neuropathy with liability to pressure palsies (HNPP) are common inherited disorders of the peripheral nervous system. The majority of CMT1 patients have a $1.5 \mathrm{Mb}$ tandem duplication (CMT1A) in chromosome 17p11.2 while most HNPP patients have a deletion of the same $1.5 \mathrm{Mb}$ region. The CMT1A duplication and HNPP deletion are the reciprocal products of an unequal crossing over event between misaligned flanking CMT1A-REP elements. We analysed 162 unrelated CMT1A duplication patients and HNPP deletion patients from 11 different countries for the presence of a recombination hotspot in the CMT1AREP sequences. A hotspot for unequal crossing over between the misaligned flanking CMT1A-REP elements was observed through the detection of novel junction fragments in $76.9 \%$ of 130 unrelated CMT1A patients and in $71.9 \%$ of 32 unrelated HNPP patients. This recombination hotspot was also detected in eight out of 10 de novo CMT1A duplication and in two de novo HNPP deletion patients. These data indicate that the hotspot of unequal crossing over occurs in several populations independently of ethnic background and is directly involved in the pathogenesis of CMT1A and HNPP. We conclude that the detection of junction fragments from the CMT1A-REP element on Southern blot analysis is a simple and reliable DNA diagnostic tool for the identification of the CMT1A duplication and HNPP deletion in most patients.

(f Med Genet 1997;34:43-49)

Keywords: CMT; HNPP; recombination hotspot.

Charcot-Marie-Tooth neuropathy type 1 (CMT1), or hereditary motor and sensory neuropathy type I (HMSN I), is the most common autosomal dominant disorder of the peripheral nervous system. CMT1 is characterised by weakness and atrophy of distal limb muscles, diminished or absent deep tendon reflexes, pes cavus deformity, and severely slowed motor and sensory nerve conduction velocities (NCVs). De- and remyelination with onion bulb formations are observed on peri- pheral nerve biopsies. ${ }^{1}$ Hereditary neuropathy with liability to pressure palsies (HNPP) is an autosomal dominantly inherited demyelinating neuropathy of the peripheral nervous system characterised by sausage-like formations of the myelin sheaths known as tomaculae. The symptoms in HNPP can often be correlated directly with minor trauma or prolonged compression of the peripheral nerves, resulting in nerve palsies for a few days to several weeks. NCVs are slowed and sensory nerve action potentials (SNAPs) are reduced or absent in damaged nerves.

Molecular genetic studies have identified the underlying gene defects in CMT1 and HNPP. CMT1A, the major form of CMT1, is caused by a tandem duplication of a $1.5 \mathrm{Mb}$ region in chromosome $17 \mathrm{p} 11.2 .^{4-7} \mathrm{HNPP}$ is caused by the reciprocal deletion of this $1.5 \mathrm{Mb}$ region. ${ }^{8-11}$ In a recent European collaborative study it was found that $70.7 \%$ of unrelated CMT1 patients have the CMT1A duplication and that $84.0 \%$ of unrelated HNPP patients have the HNPP deletion. ${ }^{12}$ The peripheral myelin protein 22 gene (PMP22) is located within the $1.5 \mathrm{Mb}$ region duplicated in CMT1A and deleted in HNPP. ${ }^{813-16}$ Point mutations in the PMP22 gene have been found in both CMT1A patients without duplication ${ }^{17-20}$ and in an HNPP patient without deletion ${ }^{21}$ implicating the PMP22 gene in the pathogenesis of both disorders.

Unequal crossing over during meiosis has been proposed as the mechanism of both the CMT1A duplication and HNPP deletion. ${ }^{48}$ This unequal crossing over event is probably the result of the misalignment of two low copy repeat elements of $\sim 30 \mathrm{~kb}$ (CMT1A-REP) which flank the $1.5 \mathrm{Mb}$ region duplicated in CMT $1 \mathrm{~A}^{7}$ and deleted in HNPP. ${ }^{8}$ Three copies of the CMT1A-REP sequence are located on the CMT1A duplication chromosome, while one copy is detected on the HNPP deletion chromosome. ${ }^{9}$ Currently, a cloned CMT1AREP sequence is used in the DNA diagnosis of CMT1A and HNPP patients using pulsed field gel electrophoresis (PFGE). ${ }^{9112223}$

Recently a recombination hotspot was identified within the CMT1A-REP elements in a cohort of unrelated CMT1A and HNPP patients of predominantly North American descent. ${ }^{24}$ The region encompassing the hotspot of recombination was $98 \%$ identical in the proximal CMT1A-REP element and the distal CMT1A-REP element. ${ }^{24}$ This remarkably active hotspot of homologous recombination was 
identified as a $1.7 \mathrm{~kb} E c o \mathrm{RI} / N s i \mathrm{I}$ junction fragment in $75 \%$ of the CMT1A duplication patients and as a $7.8 \mathrm{~kb} E c o \mathrm{RI} / E c o \mathrm{RI}$ junction fragment in $84 \%$ of the HNPP deletion patients examined. These junction fragments resulting from the unequal crossing over event between misaligned CMT1A-REP elements are stably inherited with the disease phenotypes of CMT1 and HNPP and are observed in de novo duplication and deletion patients. ${ }^{24}$ Some patients without these junction fragments appeared to have undergone a strand exchange event outside the $1.7 \mathrm{~kb}$ hotspot region but within the boundaries of the $7.8 \mathrm{~kb} \mathrm{EcoRI}$ fragment from the proximal CMT1A-REP, as indicated by dosage analysis (unpublished observation). Sequence analysis of both the proximal and the distal CMT1A-REP clones showed a mariner transposon-like element (MITE) near the hotspot of unequal recombination, which was proposed to be involved in the initiation of strand exchange events between misaligned CMT1AREPs through the generation of double strand breaks by a mariner transposase. ${ }^{24}$

In this study we estimated the frequency of this hotspot of unequal crossing over in an independent cohort of patients. A large number of unrelated CMT1A and HNPP patients of different European origin and from two other countries were screened for the presence or absence of the hotspot leading to CMT1A or HNPP. Also the frequency and origin of this hotspot was examined in a set of de novo CMT1A and HNPP patients.

\section{Materials and methods \\ PATIENT SAMPLES AND DUPLICATION/DELETION STATUS}

All 162 unrelated CMT1 and HNPP patients were screened for the presence of the CMT1A duplication or HNPP deletion according to methods previously described. ${ }^{45152526}$ Patients' DNA samples were used for research (CMT numbers) or diagnostic purposes (PN numbers). The presence and size of the CMT1A duplication or HNPP deletion was determined with restriction fragment length polymorphism (RFLP) probes pVAW409R3a (D17S122) and

Table 1 Overview of the EcoRI/SacI Southern blot results in 162 unrelated CMT1A duplication $(A)$ and HNPP deletion (B) patients of 11 different ethnic origins

\begin{tabular}{|c|c|c|c|}
\hline \multirow[t]{2}{*}{ Country } & 1 & 2 & 3 \\
\hline & $2: 3: 3: 2$ dosage & $3.2 k b$ junction & $3: 2: 2: 3$ dosage \\
\hline \multicolumn{4}{|l|}{ (A) CMT1A } \\
\hline Belgium (90) & 6 & 66 & 18 \\
\hline Germany (22) & 1 & 20 & 1 \\
\hline Israel (3) & 0 & 2 & 1 \\
\hline Lebanon (1) & 0 & 0 & 1 \\
\hline Croatia (2) & 0 & 2 & 0 \\
\hline Mali (1) & 0 & 1 & 0 \\
\hline Poland (1) & 0 & 0 & 1 \\
\hline Switzerland (1) & 0 & 1 & 0 \\
\hline Tjechia (2) & 0 & 2 & 0 \\
\hline The Netherlands (5) & 0 & 4 & 1 \\
\hline Turkey (2) & 0 & 2 & 0 \\
\hline \multirow[t]{2}{*}{ Total } & 7 & 100 & 23 \\
\hline & $2: 1: 1: 2$ dosage & $7.8 \mathrm{~kb}$ junction & $1: 2: 2: 1$ dosage \\
\hline (B) HNPP & & & \\
\hline Belgium (23) & 2 & 16 & 5 \\
\hline Germany (9) & 1 & 7 & 1 \\
\hline Total & 3 & 23 & 6 \\
\hline
\end{tabular}

1,2 , and 3 refer to the sites of unequal crossing over as shown in fig 2 . Values between parentheses represent the total number of CMT1A and HNPP patients from each country.
pEW401HE (D17S61) according to Raeymaekers et al. $^{45}$ In uninformative cases, polymorphic (CA)n repeats RM11-GT (D17S122), Mfd41 (D17S261), and AFM191xh12 (D17S921) were analysed with an automated DNA sequencer (Applied Biosystems Inc, Foster City, USA) according to Navon et $a l^{25}$ and Timmerman et al. ${ }^{23}$ Pulsed field gel electrophoresis (PFGE) was used in the remaining uninformative patients in order to detect specific CMT1A or HNPP junction fragments with probes pVAW409R $3 \mathrm{a}^{27}$ and pNEA $102 .{ }^{23}$ In some patients, fluorescence in situ hybridisation (FISH) analysis was used to prove the presence of the CMT1A duplication or HNPP deletion. ${ }^{2628}$

The clinical, electrophysiological, histopathological, and genetic data of the de novo CMT1A duplication families CMT-G, PN-9, PN-20, PN-36, PN-39, and PN-42, as well as de novo HNPP deletion family PN-97, have been described previously. ${ }^{4232930}$ In this study we included the CMT1 families PN-187, PN242, PN-412, and CMT-ER1, and the HNPP family PN-340, in which a de novo CMT1A duplication and a de novo HNPP deletion were identified using previously described molecular genetic detection methods. ${ }^{23262831}$

\section{DETECTION OF RECOMBINANT JUNCTION} FRAGMENTS

To detect novel junction fragments from the recombinant CMT1A-REPs, genomic DNA was digested with EcoRI, SacI, and NsiI according to the manufacturer's instructions (New England Biolabs and Boehringer Mannheim) in double or triple restriction digestions. The DNA probe used to detect the $3.2 \mathrm{~kb}$ and $7.8 \mathrm{~kb} E c \mathrm{ORI} / \mathrm{SacI}$ specific junction fragments in Southern blot hybridisations was pLR7.8, which is a $7.8 \mathrm{~kb} E c o$ RI fragment from proximal CMT1A-REP cosmid c56A5. The DNA probe used to detect the $1.7 \mathrm{~kb} E c o \mathrm{RI} / \mathrm{Nsi}$ junction fragment in $E c o R I / S a c I / N s i \mathrm{I}$ digests was pLR6.0, which is a $6.0 \mathrm{~kb} E c o R I$ fragment from distal CMT1A-REP cosmid c112C10. Both $E c o$ RI DNA fragments were cloned into the EcoRI site of plasmid vector pTZ19R. ${ }^{24}$ The labelled probes were prehybridised with human placental DNA and hybridised according to standard procedures previously described. ${ }^{24}$

\section{Results}

We selected 130 unrelated CMT1 patients with a $1.5 \mathrm{Mb}$ CMT1A duplication and 32 unrelated HNPP patients with the reciprocal $1.5 \mathrm{Mb}$ deletion in $17 \mathrm{p} 11.2$. The CMT1A patients were referred to our laboratories in Antwerpen (Belgium) and Erlangen (Germany) for research purposes or DNA diagnosis, and are from a variety of countries including Belgium, Germany, Israel, Croatia, Lebanon, Mali, Poland, Switzerland, The Netherlands, Tjechia, and Turkey (table 1A). The HNPP patients are from Belgium and Germany (table 1B). All patients were initially screened for the presence of a recombination hotspot in the CMT1A-REP sequences using EcoRI/SacI 


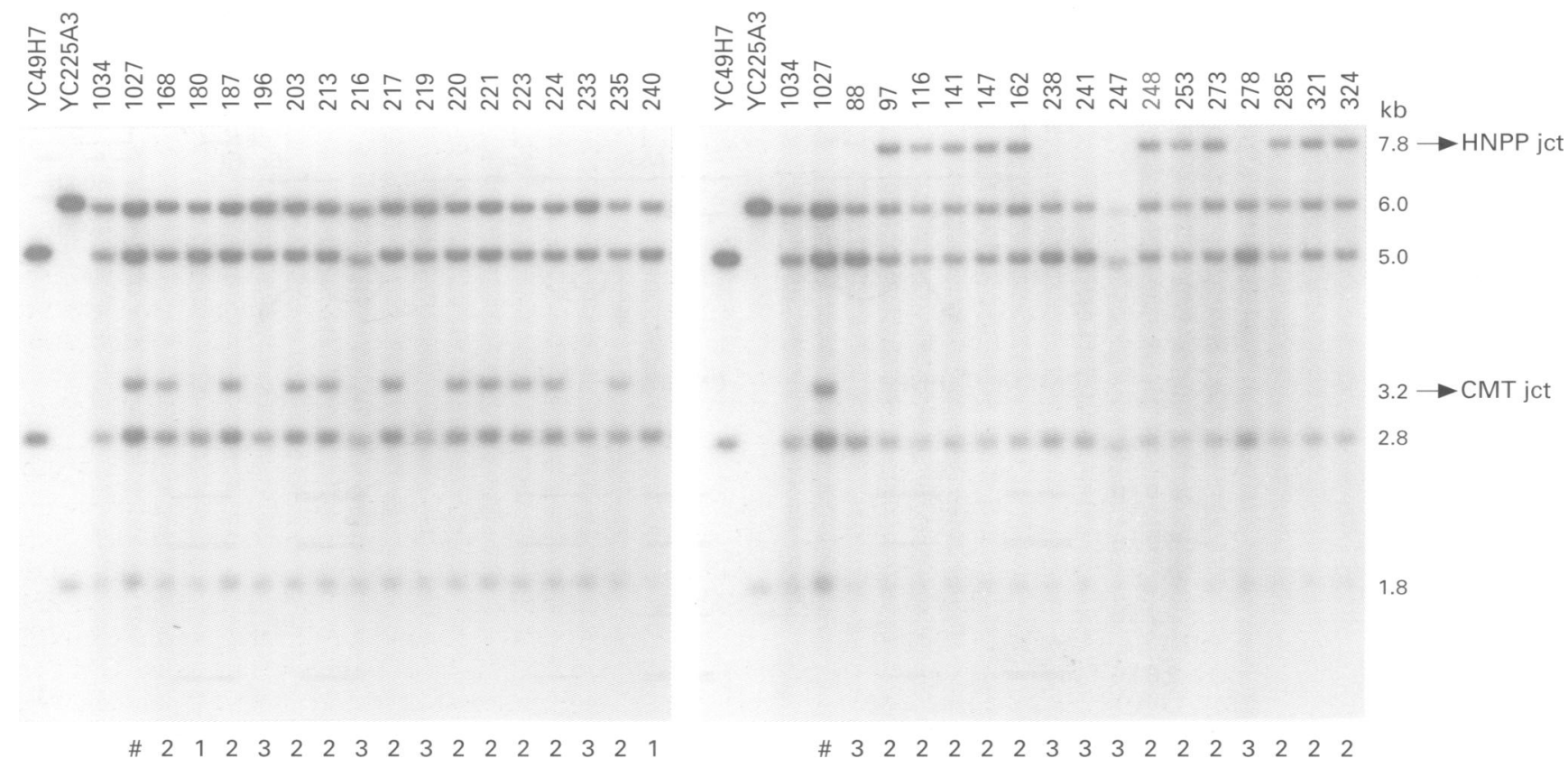

Figure 1 EcoRI/SacI Southern blot of unrelated CMT1A $(A)$ and unrelated HNPP $(B)$ patients hybridised with CMT1A-REP probe pLR7.8. Lanes YC49H7 and YC225A3 contain YAC DNA. The $5.0 \mathrm{~kb}$ and $2.8 \mathrm{~kb}$ EcoRI fragments are unique to YAC YC49H7 which spans the proximal CMT1A-REP. The $6.0 \mathrm{~kb}$ and $1.8 \mathrm{~kb}$ EcoRI fragments are unique to YAC YC225A3 which spans the distal CMT1A-REP' Lane 1034 is a normal control without CMT1A duplication or HNPP deletion, and lane 1027 is a CMT1 patient with a $1.5 \mathrm{Mb}$ CMT1A duplication. ${ }^{24}$ The numbers 1,2 , and 3 below the lanes refer to fig 2 and indicate the sites of strand exchange as determined by the detection of novel junction fragments (2) or dosage of bands (1 or 3).

double digests and Southern blot hybridisation with the CMT1A-REP probe pLR7.8 (fig 1). A $3.2 \mathrm{~kb}$ EcoRI/SacI junction fragment was identified in 100 out of 130 CMT1A duplication patients $(76.9 \%)$ and a $7.8 \mathrm{~kb} \mathrm{EcoRI/}$ $E c o$ RI junction fragment was observed in 23 out of 32 HNPP deletion patients (71.9\%). These data indicated that there is a frequent recombination site between the $E c o$ RI site unique to the distal CMT1A-REP and the SacI site unique to the proximal CMT1A-REP. This unequal crossing over event between the CMT1AREPs resulting in the CMT1A duplication or the HNPP deletion is illustrated in fig 2 .

In the remaining CMT1A and HNPP patients no junction fragments were observed but dosage differences in the $6.0 \mathrm{~kb}, 5.0 \mathrm{~kb}$, $2.8 \mathrm{~kb}$, and $1.8 \mathrm{~kb}$ fragments could be detected (fig 1). These dosage differences in the hybridisation signals are most likely because of unequal crossing over events just outside the hotspot region (fig 2,1 and 3 ). The hybridisation pattern 2:3:3:2 (1) was observed in seven CMT1A duplication patients (5.3\%), and the pattern $2: 1: 1: 2$ (1) was found in three HNPP deletion patients $(9.1 \%)$, indicating that in these patients the unequal crossing over event occurred in or proximal to region 1. A dosage pattern of $3: 2: 2: 3$ (3) is found in 23 CMT1A duplication patients $(17.9 \%)$ and a pattern of $1: 2: 2: 1$ (3) is observed in six HNPP deletion patients $(18.2 \%)$, indicating a strand exchange event in or distal to region 3. An overview of the $E c o R I / S a c I$ junction fragments and dosages detected in the 162 unrelated
CMT1A duplication and HNPP deletion patients from 11 different countries are shown in table 1 . Some digestions and hybridisations were performed twice in order to confirm the reproducibility of the results. The data obtained by visual inspection of the autoradiographs were consistent with the results of the densitometric analysis (data not shown).

DNA sequence analysis of the $7.8 \mathrm{~kb}$ region containing the junction fragment boundaries in regions 1,2 , and 3 (fig 2 ) showed restriction sites which are unique to either the proximal or distal CMT1A-REP. ${ }^{24}$ An NsiI site unique to the proximal CMT1A-REP was used by Reiter $e t a l^{4}$ to refine the region of strand exchange further. Southern blot analysis of $E c o R I / S a c I / N s i$ triple digested DNA of unrelated CMT1A duplication patients hybridised with probe pLR6.0 showed a $1.7 \mathrm{~kb}$ $E c o$ RI/Nsi junction fragment in all CMT1A patients with the $3.2 \mathrm{~kb} E c o R I / S a c I$ junction fragment. Also, a $7.8 \mathrm{~kb} E c o R I / E c o R I$ junction fragment is observed by Southern analysis with probe pLR6.0 hybridised to EcoRI/SacI/NsiI triple digested DNA of the unrelated HNPP patients (data not shown). This observation indicates that the region of strand exchange in the majority of CMT1A duplication and HNPP deletion patients of non-North American descent is located between the EcoRI site unique to the distal CMT1A-REP and the NsiI site unique to the proximal CMT1A-REP. A relative risk calculation indicates that the strand exchange event in both CMT1A and HNPP patients occurs within the $1.7 \mathrm{~kb}$ hotspot pref- 


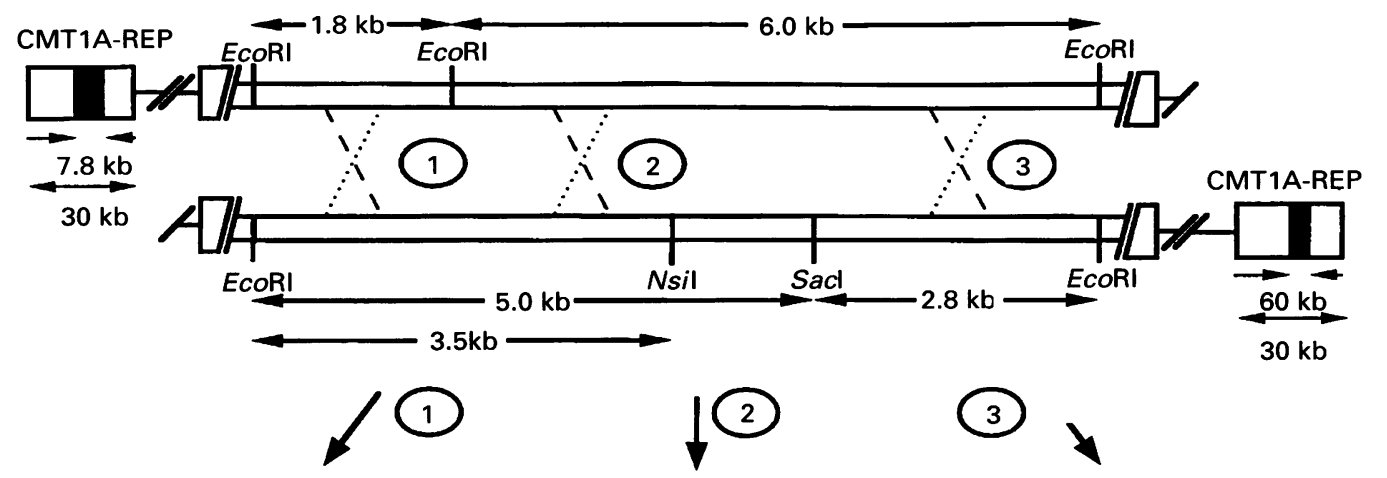

CMT1A HNPP

CMT1A HNPP

CMT1A HNPP

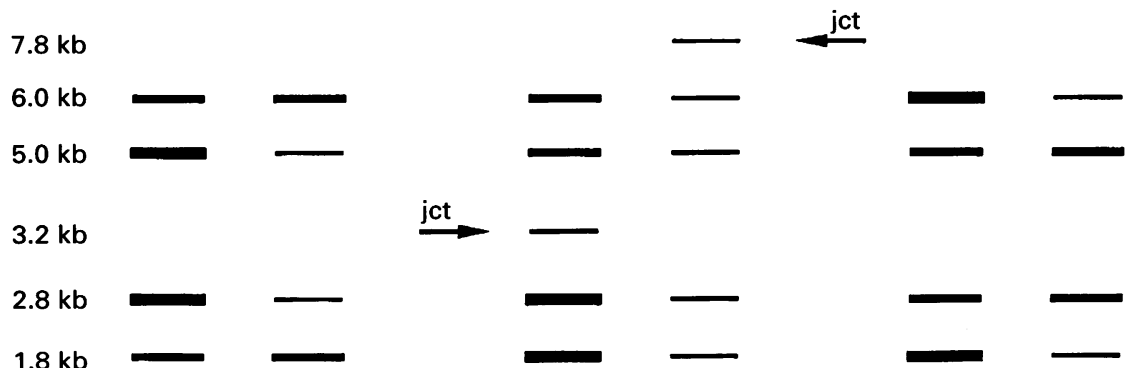

Figure 2 Crossover junctions in CMT1A duplication and HNPP deletion patients. Shown above are the proximal and distal $30 \mathrm{~kb} C M T 1 A-R E P$ s illustrating the misalignment of the $7.8 \mathrm{~kb}$ region with the distal CMT1A-REP (top) with the $7.8 \mathrm{~kb}$ region from the proximal CMT1A-REP (below). Dashed lines represent strand exchange events leading to duplication $(C M T 1 A)$ and deletion $(H N P P)$. Three potential crossover regions are illustrated $(1,2$, and 3$)$. The majority of CMTIA and HNPP patients examined undergo a strand exchange event between the EcoRI site unique to the distal CMT1A-REP and the NsiI site unique to the proximal CMT1A-REP (crossover 2). At the bottom of the figure are the predicted Southern blot patterns and allele dosages for CMT1A duplication and HNPP deletion patients where the genomic DNA was digested with SacI and EcoRI. The $3.2 \mathrm{~kb}$ and $7.8 \mathrm{~kb}$ EcoRI/SacI junction fragments as well as other restriction fragments originating from the normal and recombinant $C M T 1 A-R E P S$ detected by probe pLR7.8 are indicated. The dosages indicated for the $6.0 \mathrm{~kb}: 5.0 \mathrm{~kb}: 2.8 \mathrm{~kb}: 1.8 \mathrm{~kb}$ alleles are (1) CMT1A $(2: 3: 3: 2)$ and HNPP (2:1:1:2), (2) CMT1A (2:2:3:3) and HNPP (1:1:1:1), and (3) CMT1A (3:2:2:3) and HNPP (1:2:2:1).

erentially 52:1 over the surrounding $\sim 28 \mathrm{~kb}$ of sequence homology between the repeats. Furthermore, this hotspot of homologous re- combination was detected in unrelated CMT1A patients from 11 different countries (data not shown).
A

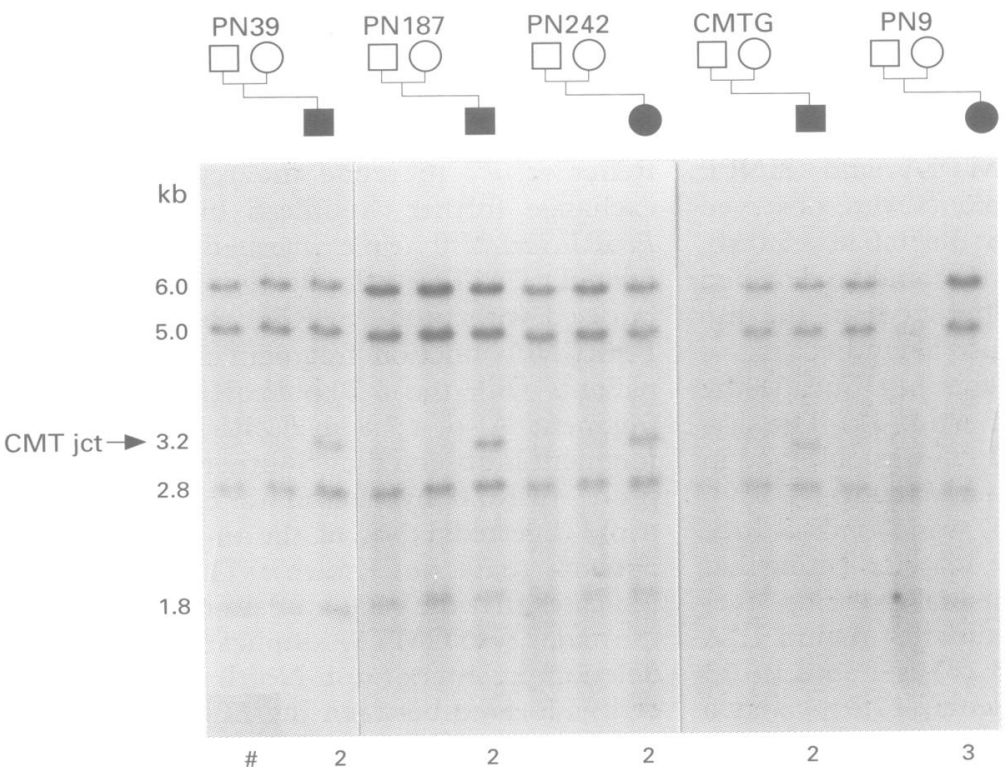

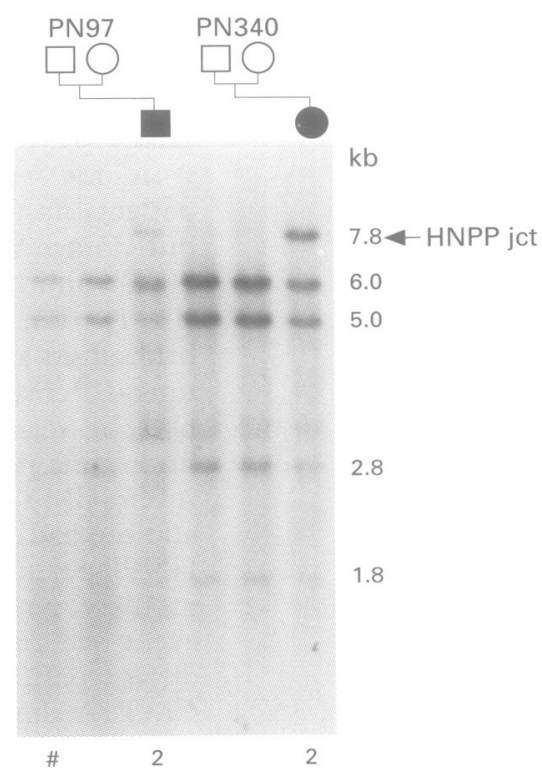

Figure 3 EcoRI/SacI Southerm blot of five de novo CMT1A $(A)$ and two HNPP $(B)$ families hybridised with CMT1A-REP probe pLR7.8. Only Figure 3 EcoRISAcI Southern blot of five de novo CMTIA (A) and two HNPP (B) families hybridised with the unaffected parents and their affected child of each family are shown. Filled symbol absence of a $3.2 \mathrm{~kb}$ junction fragment in CMT1A de novo patient PN-9. This 20, PN-36, PN-42, PN-412, and CMTER1 are not shown. Note the absence of a $3.2 \mathrm{~kb}$ junction fragment at or proximal to 3 in fig 2 . 

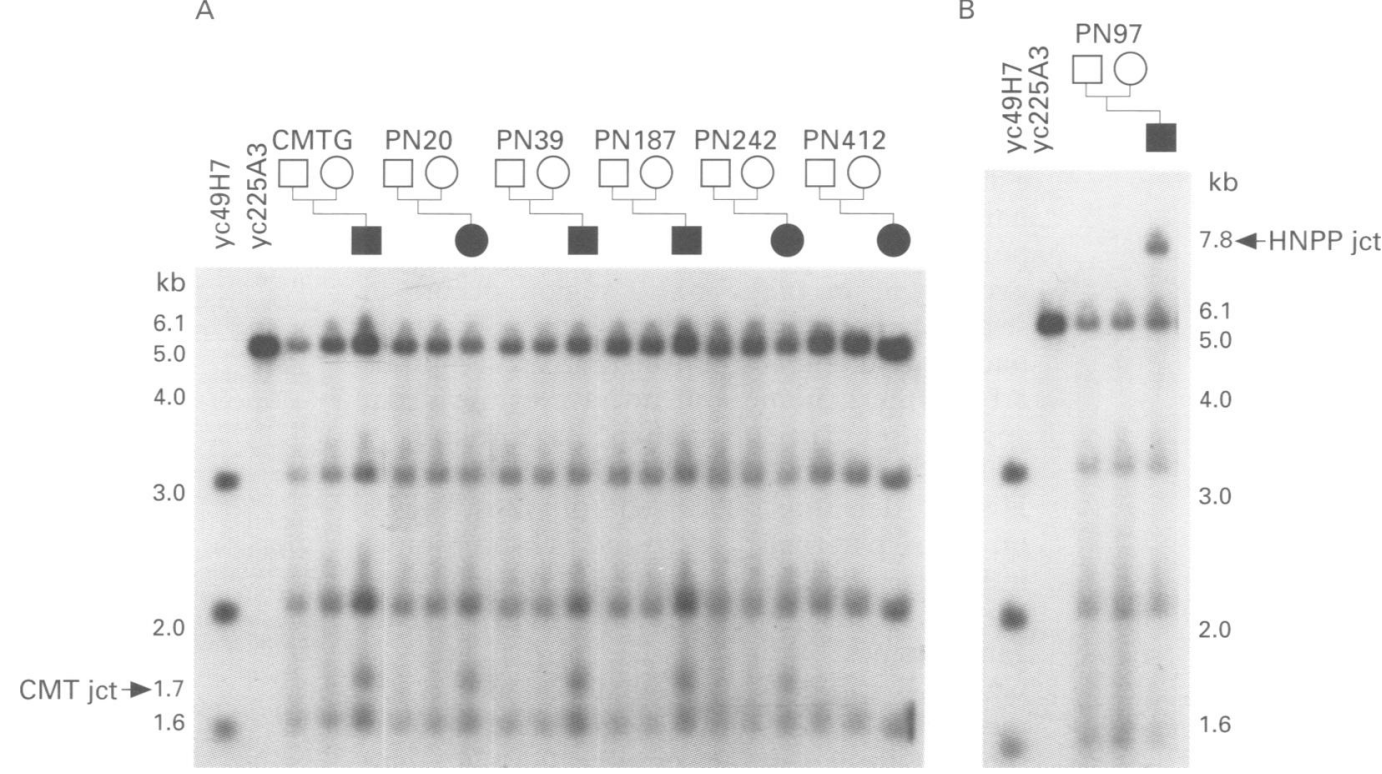

Figure 4 EcoRI/SacI/NsiI Southern blot of six de novo CMT1A $(A)$ and one HNPP (B) families hybridised with CMT1A-REP probe pLR6.0. Lanes YC49H7 and YC225A3 contain YAC DNA. The 5.0 kb, 3.8kb, 2.8kb, and $1.6 \mathrm{~kb}$ fragments are unique to YAC YC49H7 which spans the proximal CMT1A-REP. The $6.0 \mathrm{~kb}$ EcoRI fragment is unique to YAC YC225A3 which spans the distal CMT1A-REP. The hybridisation data of CMT1A families PN-9, $P N-36, P N-42$, and CMTER1, and of HNPP family PN-340 are not shown. Note the absence of a $1.7 \mathrm{~kb}$ junction fragment in CMT1A de novo patient PN-412.

In this study we also analysed 10 de novo CMT1A and two de novo HNPP families for the presence of the recombination hotspot. In all cases the unequal crossing over event was of paternal origin, as indicated by RFLP and (CA)n repeat analysis of DNA markers located within the CMT1A/HNPP region (data not shown). Using the CMT1A-REP probe pLR7.8 we observed the $3.2 \mathrm{~kb} E c \mathrm{RI} / \mathrm{SacI}$ junction fragment on EcoRI/SacI Southern blots in $8 / 10$ de novo CMT1A duplication patients and the $7.8 \mathrm{~kb} E c o \mathrm{RI} / E c o \mathrm{RI}$ junction fragment in two de novo HNPP deletion patients. The $E c \mathrm{RI} / \mathrm{SacI}$ hybridisation patterns of five CMT1A and two HNPP de novo families are shown in fig 3. The CMT1A 3:2: $2: 3$ (3) dosage pattern was observed in the affected daughter of family PN-9 (fig 3A). The $1.7 \mathrm{~kb} E c o \mathrm{RI} / \mathrm{Nsi}$ junction fragment was found in 8/9 de novo CMT1A duplication patients and the $7.8 \mathrm{~kb} E c o \mathrm{RI} / E c o \mathrm{RI}$ junction fragment in two de novo HNPP deletion patients. The EcoRI/SacI/NsiI hybridisation patterns of six CMT1A and one HNPP de novo families are shown in fig 4 . These data support the hypothesis that a $1.7 \mathrm{~kb} E c o \mathrm{RI} / N s i \mathrm{I}$ recombination hotspot for unequal crossing over results in the CMT1A duplication and HNPP deletion.

\section{Discussion}

Previous studies suggested that unequal crossing over between homologous chromosomes was a mechanism for the generation of the CMT1A duplication and HNPP deletion. ${ }^{48}$ Physical mapping studies showed the presence of two low copy repeat elements of at least $30 \mathrm{~kb}$ (CMT1A-REP) which flank the $1.5 \mathrm{Mb}$ region duplicated in CMT1A patients ${ }^{7}$ and deleted in HNPP patients. ${ }^{9}$ The CMT1A-REP repeats are present in the CMT1A duplication and HNPP deletion specific junction fragments detected by Southern blot and PFGE analysis. ${ }^{1123}$ The analysis of dosage patterns for CMT1A-REP specific junction fragments suggested a preferential region for crossing over events between CMT1A-REPs. ${ }^{9-11} 2332-34$

Reiter et $a l^{4}$ showed the presence of a recombination hotspot associated with the reciprocal recombination which leads to DNA rearrangements resulting in both CMT1A and HNPP. The recombination hotspot was defined by identifying rearrangement specific junction fragments which reflect crossing over events occurring between restriction sites that are unique to either the proximal or distal CMT1AREP sequence. The hotspot was determined by scoring the number of people with crossover events in the small $1.7 \mathrm{~kb}$ region flanked by $E c o$ RI and $N s i \mathrm{I}$ in the recombinant CMT1AREP and comparing these to the number of crossovers in the remaining $\sim 28 \mathrm{~kb}$ of the CMT1A-REP region. These experiments indicated that there is a 53:1 preference for strand exchange in the small region bounded by the unique EcoRI and $N s i \mathrm{I}$ sites. ${ }^{24}$ We observed that $76.9 \%$ of CMT1A duplication patients had the $1.7 \mathrm{~kb} E c o \mathrm{RI} / N s i \mathrm{I}$ junction fragment. CMT1A duplication patients without this novel junction fragment had dosage differences similar to those predicted if the crossing over event had occurred proximal to the EcoRI site in the distal CMT1A-REP or distal to the NsiI site in the proximal CMT1A-REP. In HNPP deletion patients, $71.9 \%$ had the $7.8 \mathrm{~kb} E c o \mathrm{RI} /$ $E c o$ RI junction fragment indicative of a strand exchange event within this $1.7 \mathrm{~kb}$ region. In this study, the relative risk for strand exchange in the $1.7 \mathrm{~kb} E c o \mathrm{RI} / \mathrm{Nsi}$ I hotspot region was 52 : 1 , confirming the findings of Reiter $e t a l^{4}$ and indicating that in most cases the site of strand exchange is between the EcoRI site unique to 
the distal CMT1A-REP and the NsiI site unique to the proximal CMT1A-REP. The $1.7 \mathrm{~kb}$ hotspot of recombination in the CMT1A-REP elements leading to CMT1A duplication and HNPP deletion was found in a large set of unrelated CMT1A and HNPP patients of different ethnic origin. Thus, the hotspot responsible for the unequal crossing over event in the $17 \mathrm{p} 11.2$ region occurs in several populations independent of ethnic background and is an intrinsic structural property of the genome and not a polymorphism specific to a particular genetic background.

The de novo CMT1A duplications and HNPP deletions occurred in most cases on the paternally inherited chromosome, indicating that the unequal crossing over event occurs preferentially during male gametogenesis. ${ }^{48293035-38}$ De novo cases of CMT1A and HNPP of maternal origin are rare. ${ }^{32}{ }^{38-41}$ In this study, we analysed the DNA samples from several sporadic CMT1A and HNPP cases with paternal origin of the duplication or deletion. The $1.7 \mathrm{~kb} E c o \mathrm{RI} / N s i \mathrm{I}$ junction fragment was found in $8 / 9$ de novo CMT1A patients and the $7.8 \mathrm{~kb} E c o R I / E c o R I$ fragment was observed in two de novo HNPP deletion patients. These junction fragments were not detected in the parents of the affected subjects indicating that there is a correlation between the CMT1A/HNPP phenotypes and the appearance of the junction fragments. The detection of these novel junction fragments in de novo CMT1A cases rules out the possiblility that they are merely polymorphisms which segregate with the disease phenotype in selected populations. In fact, the de novo appearance of these junction fragments in affected patients of both North American and European decent suggests that the homologous recombination event between misaligned CMT1A-REPs is caused by an intrinsic genomic charateristic which is not susceptible to the influence of various genetic backgrounds.

Dosage patterns were previously observed with CMT1A-REP probe pNEA102 on EcoRI Southern blots of unrelated CMT1A duplication and HNPP deletion patients..$^{9-112332-34}$ The detection of junction fragments from the recombinant CMT1A-REP in CMT1A and HNPP patients on EcoRI/SacI or EcoRI/SacI/ $N s i \mathrm{I}$ Southern blot analysis is more readily interpreted and gives more consistent results than dosage analysis of hybridisation signals detected with pNEA102. ${ }^{42}$ Restriction fragment patterns and allele dosages for CMT1A and HNPP patients who undergo a strand exchange outside the $1.7 \mathrm{~kb}$ hotspot region could be used to predict whether the recombination junctions in these patients are located proximal (crossover 1 or proximal to the leftmost EcoRI site) or distal (crossover 3 or distal to the rightmost $E c o$ RI site) to the hotspot (fig 2). The development of a PCR method for the detection of CMT1A and HNPP recombinant junctions would be quite useful for fast and accurate mutation screening of most CMT1 and HNPP patients. However, some CMT1A and HNPP patients apparently undergo strand exchange events just outside the hotspot region and other rare patients have been reported with larger or smaller duplications or deletions. ${ }^{29} 3143$ These patients will most likely have other breakpoints located within or outside the $1.5 \mathrm{Mb}$ CMT1A/HNPP region and will require alternate detection methods.

The first two authors contributed equally to the preparation of this manuscript. We are grateful to the clinicians who provided us with DNA material as well as the patients and their relatives for their kind cooperation in our research project. We would like to thank Els De Vriendt and Arif Ekici for their excellen technical assistance. Part of this work was performed at Baylor College of Medicine by VT and BR. BR wishes to thank Prof Dr B Neuendörfer and Prof Dr R-A Pfeiffer for their continued support. This work was supported in part by grants from the Belorian National Fund for Scientific part by grants from the special research fund of the University of Antwerp to and a special research fund of the University of Antwerp to CVB, "Dom the "Deutsche Forschungsgemeinschaft" (DFG) and the "Deutsche Gesellschaft Muskelkranke" (DGM) to BR, the Boehringer Ingelheim Funds and the Herbert-Quandt-Foundaion of the VARTA AG Inc to TL, and the United States JRL VT and EN are research ssistants of the NFSR, Belgium.

1 Dyck PJ, Chance PE, Lebo RV, Carney JA. Hereditary motor and sensory neuropathies. In: Dyck PJ, Thomas PK, Griffin JW, Low PA, Poduslo JF, eds. Peripheral neuropathy. Philadelphia: Saunders, 1993:1094-136.

2 Windebank AJ. Inherited recurrent focal neuropathies. In Dyck PJ, Thomas PK, Griffin JW, Low PA, Poduslo JF eds. Peripheral neuropathy. Philadelphia: Saunders, 1993. 1137-148

3 Harding AE. From the syndrome of Charcot-Marie-Tooth to disorders of peripheral myelin proteins. Brain 1995; 118:809-18.

4 Raeymaekers P, Timmerman V, Nelis E, et al and the HMSN Collaborative Research Group. Duplication in chromosome $17 \mathrm{p} 11.2$ in Charcot-Marie-Tooth neuropathy type 1a (CMT 1a). Neuromusc Disord 1991;1:93-7.

5 Raeymaekers P, Timmerman V, Nelis E, et al and the HMSN Collaborative Research Group. Estimation of the size of the chromosome 17p11.2 duplication in Charcot-MarieTooth neuropathy type 1a (CMT1a). f Med Genet 1992; 29:5-11.

6 Lupski JR, Montes de Oca-Luna R, Slaugenhaupt S, et al. DNA duplication associated with Charcot-Marie-Tooth disease type 1a. Cell 1991;66:219-32.

7 Pentao L, Wise CA, Chinault AC, Patel PI, Lupski JR. Charcot-Marie-Tooth type $1 \mathrm{~A}$ duplication appears to arise from recombination at repeat sequences flanking the $1.5 \mathrm{Mb}$ monomere unit. Nat Genet 1992;2:292-300.

8 Chance PF, Alderson MK, Leppig KA, et al. DNA deletion associated with hereditary neuropathy with liability to pressure palsies. Cell 1993;72:143-51.

9 Chance PF, Abbas N, Lensch NW, et al. Two autosomal dominant neuropathies result from reciprocal DNA duplication/deletion of a region on chromosome 17. Hum Mol Genet 1994;3:223-8.

10 LeGuern E, Sturz F, Gugenheim M, et al. Detection of deletion within $17 \mathrm{p} 11.2$ in 7 French families with hereditary neuropathy with liability to pressure palsies (HNPP). Cytogenet Cell Genet 1994;65:261-4.

11 Lorenzetti D, Pareyson D, Sghirlanzoni A, et al. A $15 \mathrm{Mb}$ deletion in $17 \mathrm{p} 11.2$-p12 is frequently observed in Italian families with hereditary neuropathy with liability to presfamilies with hereditary neuropathy with liabilit

12 Nelis E, Van Broeckhoven C. Estimation of the mutation frequencies in Charcot-Marie-Tooth disease type 1 and hereditary neuropathy with liability to pressure palsies: a hereditary neuropathy with liability to pressure palsies: a European.

13 Matsunami N, Smith B, Ballard L, et al. Peripheral myelin protein-22 gene maps in the duplication in chromosome 17p11.2 associated with Charcot-Marie-Tooth 1A. Nat Genet 1992;1:176-9.

14 Patel PI, Roa BB, Welcher AA, et al. The gene for the peripheral myelin protein PMP-22 is a candidate for $\mathrm{Ch}$ arcot-Marie-Tooth disease type 1A. Nat Genet 1992;1 $159-65$.

15 Timmerman V, Nelis E, Van Hul W, et al. The periphera myelin protein gene PMP-22 is contained within the Charcot-Marie-Tooth disease type 1A duplication. Nat Genet 1992;1:171-5.

16 Valentijn LJ, Bolhuis PA, Zorn I, et al. The peripheral myelin gene PMP-22/GAS-3 is duplicated in Charcot-MarieTooth disease type 1A. Nat Genet 1992;1:166-70.

17 Valentijn LJ, Baas F, Wolterman RA, et al. Identical poin mutations of PMP-22 in Trembler-J mouse and CharcotMarie-Tooth disease type 1A. Nat Genet 1992;2:288-91.

18 Roa BB, Garcia CA, Suter U, et al. Charcot-Marie-Tooth type 1A: association with a spontaneous point mutation in the PMP22 gene. $N$ Engl $\mathcal{Y}$ Med 1993;329:96-101.

19 Roa, BB, Garcia CA, Pentao L, et al. Evidence for a recessive PMP-22 point mutation in Charcot-Marie-Tooth disease PMP-22 point mutation in Charcot-M

20 Nelis E, Timmerman V, De Jonghe P, Van Broeckhoven C. Identification of a $5^{\prime}$ splice site mutation in the PMP-22 Identification of a 5 splice site mutation in the PMP-22 gene in autosomal dominant Charcot-Ma
type 1. Hum Mol Genet 1994;3:515-16. 
21 Nicholson GA, Valentijn LJ, Cherryson AK, et al. A frame shift mutation in the PMP22 gene in hereditary neuropathy with liability to pressure palsies. Nat Genet 1994;6:263-6.

22 Roa BB, Ananth U, Garcia CA, Lupski JR. Molecular diagnosis of CMT1A and HNPP. Labmed Int 1995;12: 22-4.

23 Timmerman V, Löfgren A, LeGuern E, et al. Molecula genetic analysis of the $17 \mathrm{p} 11.2$ region in patients with hereditary neuropathy with liability to pressure palsies (HNPP). Hum Genet 1996;97:26-34.

24 Reiter LT, Murakami T, Koeuth T, et al. A recombination hotspot responsible for two inherited peripheral neuropathies is located near a mariner transposon-like element. Nat Genet 1996;12:288-97.

25 Navon R, Timmerman V, Löfgren A, et al. Prenatal diagnosis of Charcot-Marie-Tooth disease type 1A (CMT1A) using molecular genetic techniques. Prenat Diagn 1995;15:63340 .

26 Liehr T, Thoma K, Kammler K, et al. Direct preparation of uncultured EDTA-treated or heparinized blood for

27 interphase FISH analysis. Appl Cytogenet 1995;6:185-8. hoven C. Mutation detection and diagnosis using PFGE In: Monaco AP, ed. Pulsed field gel electrophoresis: a practical In: Monaco AP, ed. Pulsed field gel electrophoresis: a pra

$28 \mathrm{Liehr}$ T, Rautenstrauss B, Grehl H, et al. Mosaicism for the Charcot-Marie-Tooth disease type 1A duplication suggests somatic reversion Hum Genet 1996;98:22-8.

29 Palau F, Löfgren A, De Jonghe P, et al. Origin of the de novo duplication in Charcot-Marie-Tooth disease type 1A: unequal nonsister chromatid exchange during spermatogenesis. Hum Mol Genet 1993;2:2031-5.

30 Verhalle D, Löfgren A, Nelis E, et al. Deletion in the CMT1A locus on chromosome $17 \mathrm{p} 11.2$ in hereditary neuropathy with liability to pressure palsies. Ann Neurol 1994;35:704-8.

31 Ionasescu VV, Ionasescu R, Searby C, Barker DF. CharcotMarie-Tooth neuropathy type IA with both duplication and non-duplication. Hum Mol Genet 1993;2:405-10.

32 LeGuern $\mathrm{E}$, Gouider $\mathrm{R}$, Ravisé $\mathrm{N}$, et al A de novo case of hereditary neuropathy with liability to pressure palsies
(HNPP) of maternal origin: a new mechanism for deletion in 17p11.2? Hum Mol Genet 1996;5:103-6.

33 Tyson J, Malcolm S, Thomas PK, Harding AE. Deletion of chromosome 17p11.2 in multifocal neuropathies. Ann Neurol 1996;39:180-6.

34 Kiyosawa H, Lensch MW, Chance PF. Analysis of the CMT1A-REP repeat: mapping crossover breakpoints in CMT1A and HNPP. Hum Mol Genet 1996;4:2327-34.

35 Wise CA, Garcia CA, Davis SN, et al. Molecular analyses of unrelated Charcot-Marie-Tooth (CMT) disease patients suggest a high frequency of the CMT1A duplication. $A m$ 7 Hum Genet 1993;53:853-63.

36 Mariman ECM, Gabreëls-Festen AAWM, et al. Prevalence of the $15 \mathrm{Mb} 17 \mathrm{p}$ deletion in families with hereditary neuropathy with liability to pressure palsies. Ann Neurol 1994;36:650-5.

37 Hertz JM, Borglum AD, Brandt CA, Flint T, Bisgaard C Charcot-Marie-Tooth disease type 1A: the parental origin of a de novo 17p11.2-p12 duplication. Clin Genet 1994; 46:291-4.

38 Blair IP, Nash J, Gordon MJ, Nicholson GA. Prevalence and origin of de novo duplications in Charcot-Marie-
Tooth disease type 1A: first report of a de novo duplication with a maternal origin. Am $\mathcal{\exists}$ Hum Genet 1996;58:472-6.

39 Reisecker R, Leblhuber F, Lexner R, Radner G, Rosenkran W, Wagner K. A sporadic form of hereditary neuropathy with liability to pressure palsies: clinical electrodiagnostic, and molecular genetic findings. Neurology 1994;44:753-5.

40 Mancardi GL, Uccelli A, Bellone E, et al. 17p11.2 duplication is a common finding in sporadic cases of CharcotMarie-Tooth type 1. Eur Neurol 1994;34:135-9.

41 Silander K, Meretoja P, Nelis E, Timmerman V, Van Broeckhoven C, Savontaus ML. A de novo duplication in $17 \mathrm{p} 11.2$ and a novel mutation in the P0 gene in two DejérineSottas syndrome patients. Hum Mutat (in press).

42 Lupski JR. DNA diagnosis for Charcot-Marie-Tooth disease and related inherited neuropathies. Clin Chem 1996;42. 995-8.

43 Valentijn LJ, Baas F, Zorn I, Hensels GW, de Visser M Bolhuis PA. Alternatively sized duplication in CharcotMarie-Tooth disease type 1A. Hum Mol Genet 1993;2: 2143-6. 